\title{
Discovery of Membrane-Bound Pyrophosphatase Inhibitors Derived from an Isoxazole Fragment
}

\author{
Niklas G. Johansson,, Ainoleena Turku, "Keni Vidilaseris, Loïc Dreano, Ayman Khattab, \\ Daniel Ayuso Pérez, Aaron Wilkinson, Yuezhou Zhang, Matti Tamminen, Evgeni Grazhdankin, \\ Alexandros Kiriazis, Colin W. G. Fishwick, Seppo Meri, Jari Yli-Kauhaluoma, Adrian Goldman,* \\ Gustav Boije af Gennäs, and Henri Xhaard*
}

Cite This: https://dx.doi.org/10.1021/acsmedchemlett.9b00537

Read Online

ABSTRACT: Membrane-bound pyrophosphatases (mPPases) regulate energy homeostasis in pathogenic protozoan parasites and lack human homologues, which makes them promising targets in e.g. malaria. Yet only few nonphosphorus inhibitors have been reported so far. Here, we explore an isoxazole fragment hit, leading to the discovery of small mPPase inhibitors with 6-10 $\mu \mathrm{M} \mathrm{IC}_{50}$ values in the Thermotoga maritima test system. Promisingly, the compounds retained activity against Plasmodium falciparum mPPase in membranes and inhibited parasite growth.

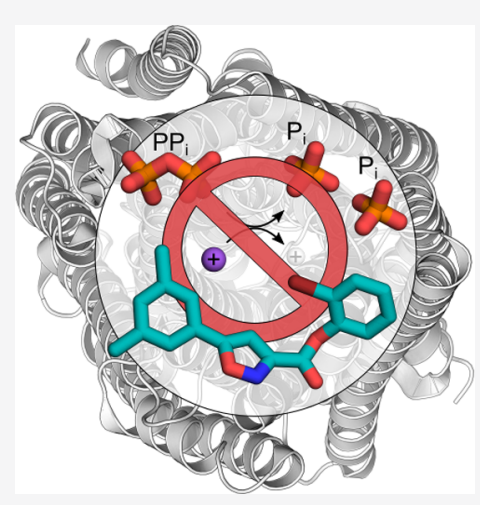

KEYWORDS: Membrane-bound pyrophosphatase, protozoan diseases, drug design, isoxazoles

$\mathrm{P}$ rotozoan diseases such as malaria and leishmaniasis affect many vertebrate species and are a major cause of human mortality or morbidity worldwide. ${ }^{1,2}$ They are caused by protist parasites such as Plasmodium spp., Toxoplasma spp., Trypanosoma spp., and Leishmania spp. Common to these parasites is the acidocalcisome, a vesicle that accumulates phosphorus compounds (e.g. bisphosphonates and polyphosphates, with concentrations of the latter estimated in the 3-5 $\mathrm{M}$ range ${ }^{3,4}$ ), metal ions such as $\mathrm{Mg}^{2+}$ and $\mathrm{Ca}^{2+}$, as well as positively charged compounds (e.g. diamines). ${ }^{5}$ These organelles have been associated with several functions: shortchain polyphosphate (poly-P) metabolism, storage of cations, calcium homeostasis, intracellular $\mathrm{pH}$ homeostasis, and osmoregulation. Acidocalcisomes and their major component poly-P are essential for the response of trypanosomatids to different types of stress, ${ }^{4}$ especially low-energy conditions. ${ }^{3,6-9}$

Parasitic protists express one or two types of membranebound pyrophosphatases (mPPases), which are the focus of this study. ${ }^{10,11} \mathrm{mPPases}$ are large $(70-81 \mathrm{kDa})$ homodimeric integral membrane proteins, consisting of 15-17 transmembrane helices per monomer, which hydrolyze pyrophosphate into orthophosphate. ${ }^{11}$ They occur in bacteria, archaea, plants, and protozoa. ${ }^{12}$ The process is coupled to active transport $\left(\mathrm{H}^{+}, \mathrm{Na}^{+}\right.$, or $\left.\mathrm{H}^{+} / \mathrm{Na}^{+}\right)$across membranes and can be regulated by monovalent cations $\left(\mathrm{K}^{+}\right.$dependence). Various $\mathrm{X}$ ray structures of the hyperthermophilic bacterium Thermotoga maritima $^{13-15}$ and mung bean Vigna radiata ${ }^{14,16} \mathrm{mPPases}$ have been solved to date by us and other researchers. Some of these structures have been cocrystallized with the substrate analogue imidodiphosphate (IDP), yet only very few nonphosphorus compounds have been reported. ${ }^{15,17}$

Membrane-bound pyrophosphatases have been suggested to be valuable targets for chemotherapeutic action. $3,10,18,19$ Indeed, siRNA-induced mPPase knockouts in Trypanosoma brucei compromised the function of its acidocalcisomes, causing severe reduction in poly-P quantity and acidocalcisome acidity. ${ }^{8}$ In Toxoplasma gondii, mPPase knockouts increased sensitivity to extracellular conditions and compromised virulence in mice. ${ }^{7}$ Additionally, in parasitic protozoa, such as P. falciparum, T. gondii, L. donovani, T. brucei, and T. cruzi, pyrophosphate (and bisphosphonate) derivatives are able to inhibit growth. ${ }^{10,20}$ However, this is thought to result from the action of both soluble and membrane-bound pyrophosphatases, ${ }^{20,21}$ in particular by inhibition of the prenyl diphosphate synthase (isoprenoid pathway). ${ }^{22}$ As a chemotherapeutic target, mPPases offer significant advantages. First, they would

Received: November 20, 2019

Accepted: February 10, 2020 
allow targeting not only the digestive vacuole in the asexual blood stage parasites but also the gametocyte stage. ${ }^{19,23,24}$ Second, since no human homologues exist, inhibitors are highly likely to be specific, provided that phosphoruscontaining compounds are avoided due to their tendency to recognize unrelated structural motifs. ${ }^{25,26}$

Here, we take advantage of our ability to assay the purified T. maritima protein on 96-well plates to discover nonphosphorus inhibitors ${ }^{27}$ useful as tool compounds for target validation and $\mathrm{X}$-ray crystallographic studies and with a translation potential into therapeutic molecules. Of the 110 compounds presented here, 46 were obtained synthetically and 64 were purchased from commercial sources. The purity of the commercial compounds was assessed independently (99 compounds in total met the $>95 \%$ purity standard).

At the start of the study, no nonphosphorus ligands were available. A pilot screen of 16 phosphate-mimicking fragments (range $143-338 \mathrm{Da}$, average $236 \mathrm{Da}$ ) at $100 \mu \mathrm{M}$ concentration was first conducted on the Thermotoga maritima mPPase (TmPPase) model system (see Supporting Information, Table S1_1). Compounds in the library contained common phosphate isosteres such as boronate, sulfone, sulfonamide, or isoxazole moieties. ${ }^{26}$ As a result of the experimental screen, four compounds (1-4) showed over $50 \%$ inhibition (Figure 1). Compounds $1-4$ all include a

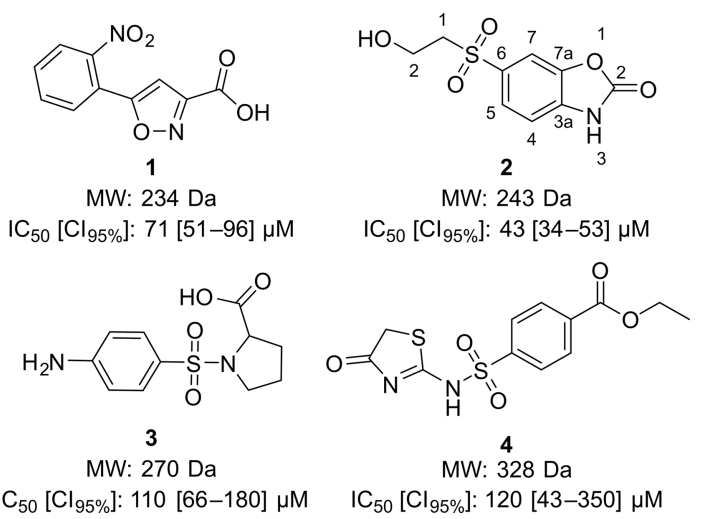

Figure 1. Top four hits identified in the pilot screen. MW, molecular weight; $\mathrm{IC}_{50}$, half maximal inhibitory concentration; $\mathrm{CI}_{95 \%}$, half maximal inhibitory concentration expressed as a $95 \%$ confidence interval (given in square brackets).

heterocyclic five-membered ring and an aryl group: $\mathbf{1}$ has a 5phenylisoxazole core $\left(\mathrm{IC}_{50}=71 \mu \mathrm{M}\right) ; 2$ contains a sulfonylsubstituted benzo $[d]$ oxazol-2 $(3 H)$-one moiety $\left(\mathrm{IC}_{50}=43\right.$ $\mu \mathrm{M})$; 3 is a benzenesulfonylproline $\left(\mathrm{IC}_{50}=110 \mu \mathrm{M}\right)$; and 4 is a sulfamoylbenzene-linked thiazolone $\left(\mathrm{IC}_{50}=120 \mu \mathrm{M}\right)$.

The isoxazole 1 was selected for further exploration. We first supplemented the series with six commercial heteroaryl analogues (see Supporting Information, Table S1 2) and seven sulfonamides (see Supporting Information, Table S1_3). The commercial availability of analogues was rather limited, and the purity of 11 other sulfonamides was insufficient (Supporting Information, Table S1_3). Screening led to the discovery of 5 (Figure 2), a rather small compound $(210 \mathrm{Da})$ with an $\mathrm{IC}_{50}$ of $17 \mu \mathrm{M}$ and a high ligand efficiency (LE 0.44). Compound $\mathbf{5}$ was used from this point on as a positive control in experimental tests, in addition to IDP. Unlike 5, the 1,5dimethyl-1H-pyrazol-4-yl analogue 6 lacked biological activity,

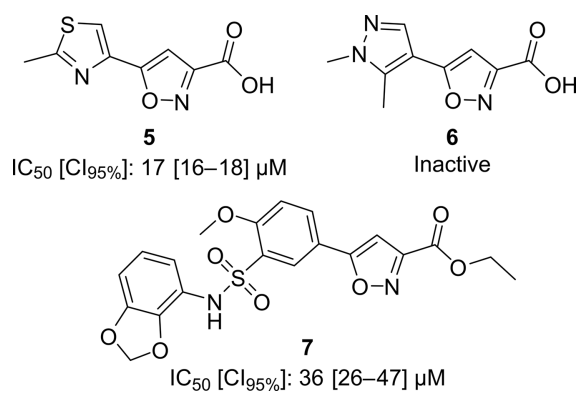

Figure 2. Selected heteroaryl analogues of 1 and the most potent hit in the sulfonamide series.

showing that not all replacements of the aryl group in $\mathbf{1}$ were tolerated.

A common feature of the other three initial hits (compounds 2-4, Figure 1) was that they contained a sulfone or sulfonamide linker. To explore the outcome of introducing sulfonamides to the 5-arylisoxazole-3-carboxylate core, we acquired analogues of $\mathbf{1}$, where primarily the ortho-nitro group had been replaced with a para-methoxy substituent (seven of them had acceptable purity). In this series (Supporting Information, Table S1_3) the most potent sulfonamide 7 (Figure 2) exhibited a 2-fold improvement in activity compared to the parent compound 1. Otherwise this exploration of aryl and sulfonamides did not provide interesting inhibitors.

The first hit series showed a loss of activity for most structural alterations of $\mathbf{1}$, except for compound $\mathbf{5}$. Building on this initial knowledge, we started a synthetic expansion around the isoxazole-3-carboxylic acid moiety of $\mathbf{1}$ and $\mathbf{5}$, introducing various phenyl substituents to the 5-position of the common core, as well as alterations to the carboxyl parts of the molecule. In total, five commercially available analogues complemented the 28 compounds synthesized at that stage (see Supporting Information, Table S1_4).

As illustrated in Scheme 1, the isoxazole series was constructed using mainly two different synthetic approaches. The isoxazole ring can be formed from e.g. substituted alkynes $^{28} \mathbf{8}$ or ketones ${ }^{29,30}$ 9. Aryl alkyne 8 and ethyl 2chloro-2-(hydroxyimino)acetate (forming nitrile oxide in situ) were used in a one-step $[3+2]$ cycloaddition reaction to give ethyl 5-arylisoxazole-3-carboxylate 10. Alternatively, 10 was obtained via a crossed condensation reaction between aryl ketone 9 and diethyl oxalate in the presence of sodium ethoxide, with a subsequent condensation reaction in the presence of hydroxylamine to form the isoxazole ring. All ethyl esters $10 a-n$ were subsequently hydrolyzed to their corresponding carboxylic acids $11 \mathbf{a}-\mathbf{n}$ with lithium hydroxide. Some of the carboxylic acids obtained $(11 i-1)$ were activated as acyl chlorides before converting them to 2-bromophenyl 5arylisoxazole-3-carboxylates $\mathbf{1 2} \mathbf{i}-\mathbf{l}$.

We started by exploring variations of the phenyl moiety by synthesizing 15 5-arylisoxazole-3-carboxylic acid derivatives. Unfortunately, no active inhibitors were obtained (Table S1_4). We first investigated 11a, with an unsubstituted phenyl ring. Substitution of the phenyl ring with electron withdrawing (as in $11 \mathrm{~b}-\mathrm{d}, 11 \mathrm{~h}$ and $11 \mathrm{~m}$ ) or donating (as in $11 \mathrm{e}-\mathrm{g}$ and 11i-1) groups did not lead to the desired activity. As part of the aryl exploration, molecular modeling suggested two positively charged interaction sites in the substrate site (K199 and K664; R191 and K499). We attempted to bridge 
Scheme 1. Main Synthesis Routes Used ${ }^{a}$

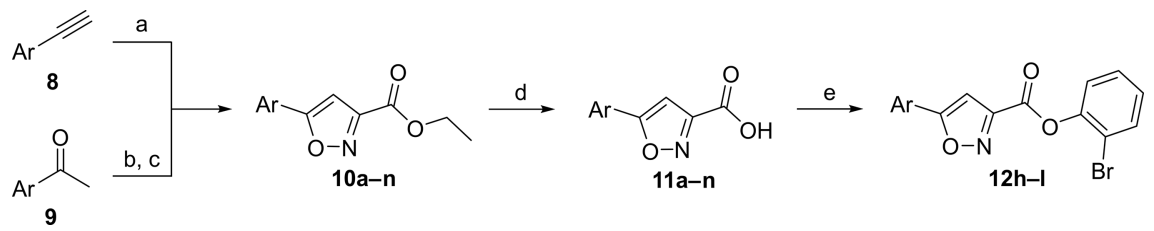

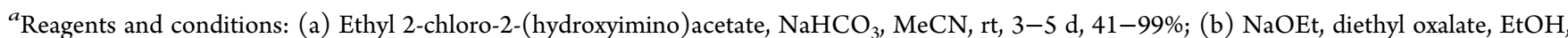
reflux, $2 \mathrm{~h}$ (for 10a) or NaOEt, diethyl oxalate, $\mathrm{EtOH} / \mathrm{Et}_{2} \mathrm{O}$, rt, overnight (for 10b-n); (c) $\mathrm{H}_{2} \mathrm{NOH} \cdot \mathrm{HCl}, \mathrm{EtOH}, \mathrm{reflux}, 3 \mathrm{~h}, 20-80 \%$ (after two steps); (d) $\mathrm{LiOH}, \mathrm{EtOH} / \mathrm{H}_{2} \mathrm{O}, 1-48 \mathrm{~h}, 42-99 \%$; (e) 2-Bromophenol, EDC.HCl, DMAP, DIPEA, DCM, rt, overnight (for 12h), 15\%, or (i) $(\mathrm{COCl})_{2}, \mathrm{DMF}, \mathrm{DCM}, \mathrm{rt}, 0.5-1 \mathrm{~h}$, (ii) 2-bromophenol, $\mathrm{Et}_{3} \mathrm{~N}, 0{ }^{\circ} \mathrm{C} \rightarrow \mathrm{rt}, 1 \mathrm{~h}$ (for $\left.12 \mathrm{i}-1\right), 28-82 \%$.

these sites. However, neither the carboxylic acid $11 \mathrm{n}$ nor the ester 10n were notably active.

Precursors of the already tested carboxylic acids (i.e., the corresponding ethyl carboxylates) were conveniently available and could be tested to expand the chemical series (Table S1_4). Generally, this set of esters did not show any biological activity, with the exception of $101\left(\mathrm{IC}_{50}=72 \mu \mathrm{M}\right)$, which was more active than its carboxylic acid analogue $\mathbf{1 1 1}$.

Initially the presence of an isoxazole core was central to the compound design. Based on the activity of 101, and due to the difficulty in obtaining active compounds, we decided to investigate a 3,5-di-tert-butylphenyl core with a set of 16 commercially available analogues (see Table 1; Supporting Information, Table S1 5). Three of these derivatives (13-15) had $\mathrm{TmPPase} \mathrm{IC}_{50}$ values in the $39-47 \mu \mathrm{M}$ range. These compounds showed a 2 -fold gain in activity compared to our starting point 1 .

We also investigated different ring replacements (see Figure 3; Supporting Information, Table S1_6). Replacing the isoxazole ring of the inactive 11a with pyrazole (as in 21) or thiazole (as in 23) led to active compounds, with at best an $\mathrm{IC}_{50}$ of $29 \mu \mathrm{M}$ for 23 .

Based on the activity of 15 (as well as the $17 \mu \mathrm{M} \mathrm{IC}{ }_{50}$ of commercially available compound SI-54, purity $87 \%$, see Table S1_7), we decided to introduce 2-bromophenyl groups to our most active compounds. Bromine atoms are useful in structural studies because the anomalous signal can aid in identifying both the presence of the molecule and its orientation in lowresolution (3.5 $\AA$ or worse) diffraction data. These 2bromophenyl carboxylate modifications were successful for compounds $12 \mathrm{~h}-\mathbf{l}$, leading to the most active compounds obtained so far (Figure 4A). The alkylated compounds $\mathbf{1 2 i - 1}$ gained up to a 77-fold activity increase $\left(\mathrm{IC}_{50}\right.$ values in the 6.1$10 \mu \mathrm{M}$ range), making them the most potent inhibitors in this study.

We also attempted to modify the thiazoles 5 (Figure 2) and 23 (Figure 3). Disappointingly, their corresponding 2bromophenyl carboxylates 25 and 26 showed a 27-fold and 1.6-fold loss in activity compared to the carboxylic acids, respectively (Figure 4B).

To obtain higher ligand efficiency for compounds $12 \mathbf{k}$ and 12l, we tried to remove some redundant atoms. One of the alkyl chains (as in $\mathbf{1 2} \mathbf{i}$ and $\mathbf{1 2} \mathbf{j}$ ) could easily be removed without any change in activity, whereas removing the bromine atom (as in 27, Figure 4C) caused a 3.6-fold loss of inhibition. We also explored changing the ester moiety of $12 \mathbf{k}$ into the corresponding amide $\mathbf{2 8}$ (Figure 4C) to increase the chemical stability and explore new interactions. However, the resulting compound was inactive. Changing the isoxazole $12 \mathrm{i}$ to the
Table 1. Selected 3,5-Di-tert-butylphenyl Analogues<smiles>CC(C)(C)c1cc(P)cc(C(C)(C)C)c1</smiles>

IC [CI95\%]

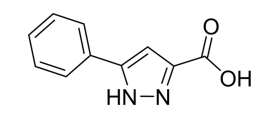

21

$\mathrm{IC}_{50}\left[\mathrm{Cl}_{95 \%}\right]: 130[85-220] \mu \mathrm{M}$

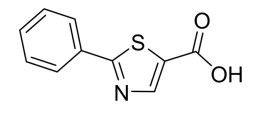

23

$\mathrm{IC}_{50}\left[\mathrm{Cl}_{95 \%}\right]: 29[26-33] \mu \mathrm{M}$
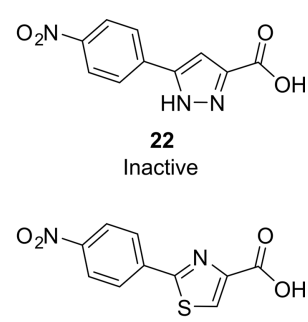

24

$\mathrm{IC}_{50}\left[\mathrm{Cl}_{95 \%}\right]: 80[66-96] \mu \mathrm{M}$

Figure 3. Selected isoxazole ring modifications. 
A<smiles>Cc1cccc(-c2cc(C(=O)Oc3ccccc3Br)no2)c1</smiles>
$12 i$<smiles>CC(C)(C)c1cccc(-c2cc(C(=O)Oc3ccccc3Br)no2)c1</smiles>

12j

$\mathrm{IC}_{50}\left[\mathrm{Cl}_{95 \%}\right]: 6.1[6.0-6.3] \mu \mathrm{M}$<smiles>Cc1cc(C)cc(-c2cc(C(=O)Oc3ccccc3Br)no2)c1</smiles>

$12 \mathrm{k}$

$\mathrm{IC}_{50}\left[\mathrm{Cl}_{95 \%}\right]: 6.9$ [6.2-7.8] $\mu \mathrm{M}$
$\mathrm{IC}_{50}\left[\mathrm{Cl}_{95 \%}\right]: 6.7$ [6.6-6.8] $\mu \mathrm{M}$<smiles>CC(C)(C)c1cc(-c2cc(C(=O)Oc3ccccc3Br)no2)cc(C(C)(C)C)c1</smiles>

$\mathrm{IC}_{50}\left[\mathrm{Cl}_{95 \%}\right]: 10$ [7.3-13] $\mu \mathrm{M}$

B<smiles>Cc1nc(-c2cc(C(=O)Oc3ccccc3Br)no2)cs1</smiles>

$\mathrm{IC}_{50}\left[\mathrm{Cl}_{95 \%}\right]: 460$ [340-640] $\mu \mathrm{M}$<smiles>O=C(Oc1ccccc1Br)c1cnc(-c2ccccc2)s1</smiles>

$\mathrm{IC}_{50}$ [Cl $\left.\mathrm{C}_{95 \%}\right]: 48$ [44-51] $\mu \mathrm{M}$<smiles>Cc1cc(C)cc(-c2cc(C(=O)Oc3ccccc3)no2)c1</smiles>

27

$\mathrm{IC}_{50}\left[\mathrm{Cl}_{95 \%}\right]: 26$ [17-42] $\mu \mathrm{M}$<smiles>Cc1cc(C)cc(-c2cc(C(=O)Nc3ccccc3Br)no2)c1</smiles>

Inactive
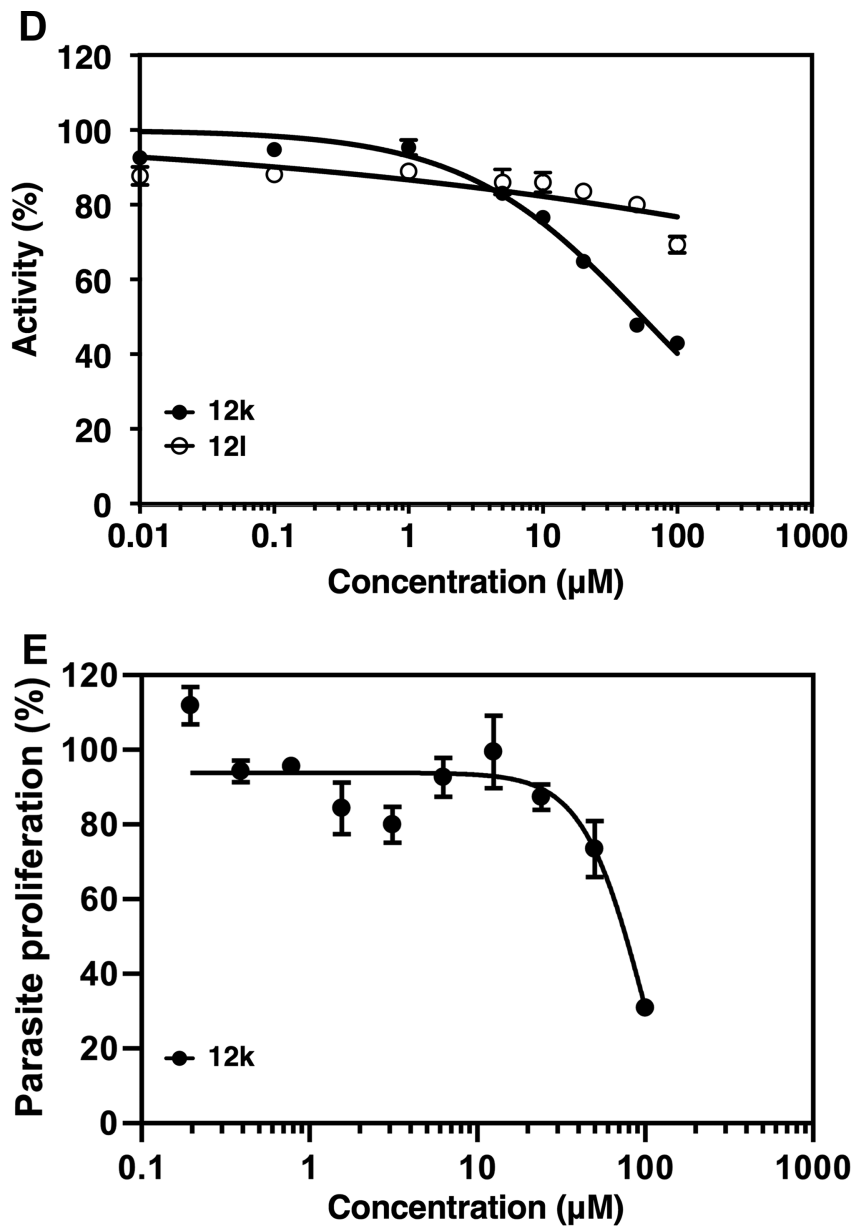

Figure 4. (A) Most potent hits of the 2-bromophenyl carboxylate series. (B) 2-Bromophenyl carboxylates of 5 and 23. (C) Selected modifications of 12k. (D) Inhibition of P. falciparum vacuolar $\mathrm{H}^{+}$-translocating pyrophosphatase (PfPPase-VP1) by 12k (filled circles) and 121 (circles). (E) Effect of $12 \mathrm{k}$ on $P$. falciparum growth. All data are shown as mean \pm SD with three replicates.

corresponding pyrazole analogue (as in SI-53) did not seem to be advantageous either.

We then addressed the potential of $12 \mathrm{k}$ and 121 for translation to pathogenic proteins. These analogues differ by replacement of two methyl groups by two tert-butyl groups. In order to do so, we expressed the PfPPase-VP1 gene (PF3D7_1456800) in baculovirus-infected insect cells and performed the inhibition assay on the PfPPase-VP1 in the membrane (the method and further analysis will be described in more detail elsewhere). Compound $\mathbf{1 2} \mathbf{k}$ was able to inhibit the PfPPase-VP1 activity with an $\mathrm{IC}_{50}=55 \mu \mathrm{M}$, whereas compound 121 did not show inhibition at the tested concentrations (Figure 4D; Supporting Information). We then tested $12 \mathbf{k}$ in a $P$. falciparum survival assay in erythrocytes, ${ }^{31,32}$ and it inhibited the growth of $P$. falciparum with an $\mathrm{IC}_{50}$ of $99 \mu \mathrm{M}$ (Figure 4E; Supporting Information). This latter finding does not prove a direct mechanism of action, since inhibition may occur e.g. through the soluble pyrophosphatase or some other mechanism. Nonetheless, taken together, these data strongly suggest that the hits discovered in this study are relevant to drug discovery against parasitic mPPases. Interestingly, similar isoxazole compounds have been found to have an $\mathrm{IC}_{50}$ of $3.3 \mu \mathrm{M}$ in $T$. cruzi parasites. $^{33}$

Herein we report a set of compounds $\left(12 \mathrm{i}, \mathrm{IC}_{50}=6.1 \mu \mathrm{M}\right.$; $12 \mathrm{j}, \mathrm{IC}_{50}=6.7 \mu \mathrm{M} ; 12 \mathrm{k}, \mathrm{IC}_{50}=6.9 \mu \mathrm{M}$; and $12 \mathrm{l}, \mathrm{IC}_{50}=10$ $\mu \mathrm{M})$ that inhibit the Thermotoga maritima mPPase and are among the first nonphosphorus inhibitors reported for that system. They were discovered through a chemical exploration of 110 compounds from a fragment hit, achieving a 10 -fold activity gain. The most potent hits possess a bromine atom, which should facilitate future structural studies. Those studies are particularly relevant since, while we used the mPPase from a hyperthermophilic bacterium as a test system, the substrate binding sites are almost entirely conserved in the mPPases of many pathogens. ${ }^{18,34}$ Preliminary tests against PfPPase-VP1 in membranes and in a parasite growth assay showed that some activity was retained, indicating their potential to be developed for target validation and therapeutic applications in parasites.

\section{ASSOCIATED CONTENT}

\section{(s) Supporting Information}

The Supporting Information is available free of charge at https://pubs.acs.org/doi/10.1021/acsmedchemlett.9b00537.

List of screened compounds (Table S1); aggregation data for key compounds 5, 12k, and 121 (Figure S1); $\mathrm{IC}_{50}$ plots from the inhibition assay; general experimental methods, synthetic procedures or commercial sources, characterization data, and KNIME workflow (PDF)

Molecular formula strings (XLSX) 


\section{AUTHOR INFORMATION}

\section{Corresponding Authors}

Adrian Goldman - Department of Biosciences, Division of Biochemistry, University of Helsinki, FI-00014 Helsinki, Finland; School of Biomedical Sciences and Astbury Centre for Structural Molecular Biology, University of Leeds, Leeds LS2 9JT, United Kingdom; Phone: +44 113 3438537; Email: a.goldman@leeds.ac.uk

Henri Xhaard - Drug Research Program, Division of Pharmaceutical Chemistry and Technology, Faculty of Pharmacy, University of Helsinki, FI-00014 Helsinki, Finland; (1) orcid.org/0000-0002-3000-7858; Phone: +358 2941 59190; Email: henri.xhaard@helsinki.fi

\section{Authors}

Niklas G. Johansson - Drug Research Program, Division of Pharmaceutical Chemistry and Technology, Faculty of Pharmacy, University of Helsinki, FI-00014 Helsinki, Finland; ๑ orcid.org/0000-0002-8226-4813

Ainoleena Turku - Drug Research Program, Division of Pharmaceutical Chemistry and Technology, Faculty of Pharmacy, University of Helsinki, FI-00014 Helsinki, Finland

Keni Vidilaseris - Department of Biosciences, Division of Biochemistry, University of Helsinki, FI-00014 Helsinki, Finland

Loïc Dreano - Drug Research Program, Division of Pharmaceutical Chemistry and Technology, Faculty of Pharmacy, University of Helsinki, FI-00014 Helsinki, Finland

Ayman Khattab - Malaria Research Laboratory, Translational Immunology Research Program, Department of Bacteriology and Immunology, Haartman Institute, University of Helsinki, FI-00014 Helsinki, Finland

Daniel Ayuso Pérez - Drug Research Program, Division of Pharmaceutical Chemistry and Technology, Faculty of Pharmacy, University of Helsinki, FI-00014 Helsinki, Finland

Aaron Wilkinson - School of Chemistry, University of Leeds, Leeds LS2 9JT, United Kingdom

Yuezhou Zhang - Drug Research Program, Division of Pharmaceutical Chemistry and Technology, Faculty of Pharmacy, University of Helsinki, FI-00014 Helsinki, Finland

Matti Tamminen - Drug Research Program, Division of Pharmaceutical Chemistry and Technology, Faculty of Pharmacy, University of Helsinki, FI-00014 Helsinki, Finland

Evgeni Grazhdankin - Drug Research Program, Division of Pharmaceutical Chemistry and Technology, Faculty of Pharmacy, University of Helsinki, FI-00014 Helsinki, Finland

Alexandros Kiriazis - Drug Research Program, Division of Pharmaceutical Chemistry and Technology, Faculty of Pharmacy, University of Helsinki, FI-00014 Helsinki, Finland

Colin W. G. Fishwick - School of Chemistry, University of Leeds, Leeds LS2 9JT, United Kingdom; 으이. orid.org/00000003-1283-2181

Seppo Meri - Malaria Research Laboratory, Translational Immunology Research Program, Department of Bacteriology and Immunology, Haartman Institute, University of Helsinki, FI-00014 Helsinki, Finland

Jari Yli-Kauhaluoma - Drug Research Program, Division of Pharmaceutical Chemistry and Technology, Faculty of Pharmacy, University of Helsinki, FI-00014 Helsinki, Finland; ๑ orcid.org/0000-0003-0370-7653

Gustav Boije af Gennäs - Drug Research Program, Division of Pharmaceutical Chemistry and Technology, Faculty of Pharmacy, University of Helsinki, FI-00014 Helsinki, Finland
Complete contact information is available at:

https://pubs.acs.org/10.1021/acsmedchemlett.9b00537

\section{Author Contributions}

${ }^{\#}$ N.G.J., A.T., and K.V. contributed equally. The manuscript was written through contributions of all authors. All authors have agreed to the final version of the manuscript.

\section{Funding}

This work was supported by grants from Jane and Aatos Erkko Foundation (to A.G., H.X., and J.Y.-K.; and to S.M. and A.K.), the Biotechnology and Biological Sciences Research Council (BBSRC, No. BB/M021610/1 to A.G.), the Academy of Finland (No. 265481 to J.Y.-K., No. 308105 to K.V., No. 310297 to H.X., and No. 1323237 to S.M.), Sigrid Jusélius Foundation (to S.M), University of Leeds (to A.W.), and University of Helsinki Research Funds (to G.B.a.G. and N.G.J.).

Notes

The authors declare no competing financial interest.

\section{ACKNOWLEDGMENTS}

The authors wish to gratefully acknowledge CSC-IT Center for Science, and the Drug Discovery and Chemical Biology (DDCB) network for computational resources; Nina Sipari and Jenna Lihavainen, from the Viikki Metabolomics UnitHelsinki Institute of Life Science (HiLIFE) for mass spectrometry services; as well as Olga Lukkonen for assistance with the experiments.

\section{ABBREVIATIONS}

DIPEA, N,N-diisopropylethylamine; poly-P, polyphosphate; siRNA, small interfering ribonucleic acid; TmPPase, Thermotoga maritima mPPase; PfPPase-VP1, Plasmodium falciparum vacuolar $\mathrm{H}^{+}$-translocating pyrophosphatase VP1

\section{REFERENCES}

(1) World Health Organization (WHO). Accelerating Progress on HIV, Tuberculosis, Malaria, Hepatitis and Neglected Tropical Diseases: A New Agenda for 2016-2030; WHO: Geneva, 2015; https://www. who.int/about/structure/organigram/htm/progress-hiv-tb-malaria$\mathrm{ntd} / \mathrm{en} /$ (accessed July 13, 2019).

(2) Golding, N.; Wilson, A. L.; Moyes, C. L.; Cano, J.; Pigott, D. M.; Velayudhan, R.; Brooker, S. J.; Smith, D. L.; Hay, S. I.; Lindsay, S. W. Integrating Vector Control across Diseases. BMC Med. 2015, 13 (1), 249.

(3) Docampo, R.; de Souza, W.; Miranda, K.; Rohloff, P.; Moreno, S. N. J. Acidocalcisomes - Conserved from Bacteria to Man. Nat. Rev. Microbiol. 2005, 3 (3), 251-261.

(4) Docampo, R.; Jimenez, V.; King-Keller, S.; Li, Z.-H.; Moreno, S. N. J. The Role of Acidocalcisomes in the Stress Response of Trypanosoma cruzi. In Advances in Parasitology; NIH Public Access, 2011; Vol. 75, pp 307-324.

(5) Mathis, A. M.; Holman, J. L.; Sturk, L. M.; Ismail, M. A.; Boykin, D. W.; Tidwell, R. R.; Hall, J. E. Accumulation and Intracellular Distribution of Antitrypanosomal Diamidine Compounds DB75 and DB820 in African Trypanosomes. Antimicrob. Agents Chemother. 2006, 50 (6), 2185-2191.

(6) Besteiro, S.; Tonn, D.; Tetley, L.; Coombs, G. H.; Mottram, J. C. The AP3 Adaptor Is Involved in the Transport of Membrane Proteins to Acidocalcisomes of Leishmania. J. Cell Sci. 2008, 121 (5), 561-570.

(7) Liu, J.; Pace, D.; Dou, Z.; King, T. P.; Guidot, D.; Li, Z. H.; Carruthers, V. B.; Moreno, S. N. J. A Vacuolar- $\mathrm{H}^{+}$-Pyrophosphatase (TgVP1) Is Required for Microneme Secretion, Host Cell Invasion, and Extracellular Survival of Toxoplasma gondii. Mol. Microbiol. 2014, 93 (4), 698-712. 
(8) Lemercier, G.; Espiau, B.; Ruiz, F. A.; Vieira, M.; Luo, S.; Baltz, T.; Docampo, R.; Bakalara, N. A Pyrophosphatase Regulating Polyphosphate Metabolism in Acidocalcisomes Is Essential for Trypanosoma brucei Virulence in Mice. J. Biol. Chem. 2004, 279 (5), $3420-3425$.

(9) Müller, S.; Coombs, G. H.; Walter, R. D. Targeting Polyamines of Parasitic Protozoa in Chemotherapy. Trends Parasitol. 2001, 17 (5), 242-249.

(10) McIntosh, M. T.; Drozdowicz, Y. M.; Laroiya, K.; Rea, P. A.; Vaidya, A. B. Two Classes of Plant-like Vacuolar-Type $\mathrm{H}^{+}$Pyrophosphatases in Malaria Parasites. Mol. Biochem. Parasitol. 2001, 114 (2), 183-195.

(11) Tsai, J. Y.; Kellosalo, J.; Sun, Y. J.; Goldman, A. Proton/Sodium Pumping Pyrophosphatases: The Last of the Primary Ion Pumps. Curr. Opin. Struct. Biol. 2014, 27 (1), 38-47.

(12) Serrano, A.; Pérez-Castiñeira, J. R.; Baltscheffsky, M.; Baltscheffsky, H. $\mathrm{H}^{+}$-PPases: Yesterday, Today and Tomorrow. IUBMB Life 2007, 59 (2), 76-83.

(13) Kellosalo, J.; Kajander, T.; Kogan, K.; Pokharel, K.; Goldman, A. The Structure and Catalytic Cycle of a Sodium-Pumping Pyrophosphatase. Science 2012, 337 (6093), 473-476.

(14) Li, K. M.; Wilkinson, C.; Kellosalo, J.; Tsai, J. Y.; Kajander, T.; Jeuken, L. J. C.; Sun, Y. J.; Goldman, A. Membrane Pyrophosphatases from Thermotoga maritima and Vigna radiata Suggest a Conserved Coupling Mechanism. Nat. Commun. 2016, 7 (1), 13596.

(15) Vidilaseris, K.; Kiriazis, A.; Turku, A.; Khattab, A.; Johansson, N. G.; Leino, T. O.; Kiuru, P. S.; Boije af Gennäs, G.; Meri, S.; YliKauhaluoma, J.; Xhaard, H.; Goldman, A. Asymmetry in Catalysis by Thermotoga maritima Membrane-Bound Pyrophosphatase Demonstrated by a Nonphosphorus Allosteric Inhibitor. Sci. Adv. 2019, 5, No. eaav7574.

(16) Lin, S. M.; Tsai, J. Y.; Hsiao, C. D.; Huang, Y. T.; Chiu, C. L.; Liu, M. H.; Tung, J. Y.; Liu, T. H.; Pan, R. L.; Sun, Y. J. Crystal Structure of a Membrane-Embedded $\mathrm{H}^{+}$-Translocating Pyrophosphatase. Nature 2012, 484 (7394), 399-403.

(17) Hirono, M.; Ojika, M.; Mimura, H.; Nakanishi, Y.; Maeshima, M. Acylspermidine Derivatives Isolated from a Soft Coral, Sinularia sp., Inhibit Plant Vacuolar $\mathrm{H}^{+}$-Pyrophosphatase. J. Biochem. 2003, 133 (6), 811-816.

(18) R. Shah, N.; Vidilaseris, K.; Xhaard, H.; Goldman, A. Integral Membrane Pyrophosphatases: A Novel Drug Target for Human Pathogens? AIMS Biophys. 2016, 3 (1), 171-194.

(19) Docampo, R.; Moreno, S. N. J. The Acidocalcisome as a Target for Chemotherapeutic Agents in Protozoan Parasites. Curr. Pharm. Des. 2008, 14 (9), 882-888.

(20) Martin, M. B.; Grimley, J. S.; Lewis, J. C.; Heath, H. T.; Bailey, B. N.; Kendrick, H.; Yardley, V.; Caldera, A.; Lira, R.; Urbina, J. A.; Moreno, S. N. J.; Docampo, R.; Croft, S. L.; Oldfield, E. Bisphosphonates Inhibit the Growth of Trypanosoma brucei, Trypanosoma cruzi, Leishmania donovani, Toxoplasma gondii. J. Med. Chem. 2001, 44 (6), 909-916.

(21) Gordon-Weeks, R.; Parmar, S.; Davies, T. G. E.; Leigh, R. A. Structural Aspects of the Effectiveness of Bisphosphonates as Competitive Inhibitors of the Plant Vacuolar Proton-Pumping Pyrophosphatase. Biochem. J. 1999, 337 (3), 373-377.

(22) Kotsikorou, E.; Song, Y.; Chan, J. M. W.; Faelens, S.; Tovian, Z.; Broderick, E.; Bakalara, N.; Docampo, R.; Oldfield, E. Bisphosphonate Inhibition of the Exopolyphosphatase Activity of the Trypanosoma brucei Soluble Vacuolar Pyrophosphatase. J. Med. Chem. 2005, 48 (19), 6128-6139.

(23) Hovlid, M. L.; Winzeler, E. A. Phenotypic Screens in Antimalarial Drug Discovery. Trends Parasitol. 2016, 32 (9), 697707.

(24) Howick, V. M.; Russell, A. J. C.; Andrews, T.; Heaton, H.; Reid, A. J.; Natarajan, K.; Butungi, H.; Metcalf, T.; Verzier, L. H.; Rayner, J. C.; Berriman, M.; Herren, J. K.; Billker, O.; Hemberg, M.; Talman, A. M.; Lawniczak, M. K. N. The Malaria Cell Atlas: Single Parasite Transcriptomes across the Complete Plasmodium Life Cycle. Science 2019, 365 (6455), No. eaaw2619.
(25) Denessiouk, K. A.; Johnson, M. S.; Denesyuk, A. I. Novel $\mathrm{C}^{\alpha} \mathrm{NN}$ Structural Motif for Protein Recognition of Phosphate Ions. J. Mol. Biol. 2005, 345 (3), 611-629.

(26) Zhang, Y.; Borrel, A.; Ghemtio, L.; Regad, L.; Boije Af Gennäs, G.; Camproux, A. C.; Yli-Kauhaluoma, J.; Xhaard, H. Structural Isosteres of Phosphate Groups in the Protein Data Bank. J. Chem. Inf. Model. 2017, 57 (3), 499-516.

(27) Vidilaseris, K.; Kellosalo, J.; Goldman, A. A High-Throughput Method for Orthophosphate Determination of Thermostable Membrane-Bound Pyrophosphatase Activity. Anal. Methods 2018, $10(6), 646-651$.

(28) Grob, J. E.; Nunez, J.; Dechantsreiter, M. A.; Hamann, L. G. Regioselective Synthesis and Slow-Release Suzuki-Miyaura CrossCoupling of MIDA Boronate-Functionalized Isoxazoles and Triazoles. J. Org. Chem. 2011, 76 (24), 10241-10248.

(29) Nagarapu, L.; Gaikwad, H. K.; Sarikonda, K.; Mateti, J.; Bantu, R.; Raghu, P. S.; Manda, K. M.; Kalvendi, S. V. Synthesis and Cytotoxicity Evaluation of 1-[3-(9H-Carbazol-4-yloxy)-2-hydroxypropyl]-3-aryl-1H-pyrazole-5-carboxylic Acid Derivatives. Eur. J. Med. Chem. 2010, 45 (11), 4720-4725.

(30) Andrzejak, V.; Muccioli, G. G.; Body-Malapel, M.; El Bakali, J.; Djouina, M.; Renault, N.; Chavatte, P.; Desreumaux, P.; Lambert, D. M.; Millet, R. New FAAH Inhibitors Based on 3-Carboxamido-5-arylisoxazole Scaffold That Protect against Experimental Colitis. Bioorg. Med. Chem. 2011, 19 (12), 3777-3786.

(31) Bennett, T. N.; Paguio, M.; Gligorijevic, B.; Seudieu, C.; Kosar, A. D.; Davidson, E.; Roepe, P. D. Novel, Rapid, and Inexpensive CellBased Quantification of Antimalarial Drug Efficacy. Antimicrob. Agents Chemother. 2004, 48 (5), 1807-1810.

(32) Smilkstein, M.; Sriwilaijaroen, N.; Kelly, J. X.; Wilairat, P.; Riscoe, M. Simple and Inexpensive Fluorescence-Based Technique for High-Throughput Antimalarial Drug Screening. Antimicrob. Agents Chemother. 2004, 48 (5), 1803-1806.

(33) De Souza, A. A. N.; Xavier, V. F.; Coelho, G. S.; Sales Junior, P. A.; Romanha, A. J.; Murta, S. M. F.; Carneiro, C. M.; Taylor, J. G. Synthesis of 3,5-Diarylisoxazole Derivatives and Evaluation of in Vitro Trypanocidal Activity. J. Braz. Chem. Soc. 2017, 29 (2), 269-277.

(34) McIntosh, M. T.; Vaidya, A. B. Vacuolar Type $\mathrm{H}^{+}$Pumping Pyrophosphatases of Parasitic Protozoa. Int. J. Parasitol. 2002, 32 (1), $1-14$. 